\title{
The Journal of Perinatology Turns a Page
}

\author{
Patrick G. Gallagher ${ }^{1,2}$
}

Received: 9 August 2019 / Accepted: 9 August 2019

(c) Springer Nature America, Inc. 2019

The beginning of 2019 has been a time of transition for the Journal of Perinatology. After almost 20 years as Editor-inChief, Dr. Ned Lawson stepped down, joining Dr. Gilbert Martin as Emeritus Editor. Under Dr. Lawson's capable leadership, the Journal of Perinatology became the flagship journal for the field of perinatology and the scientific forum for the AAP Section on Neonatal-Perinatal Medicine and the National Perinatal Association.

Ned capably led the Journal, expanding its scope, increasing its reach, and enhancing its visibility. He did this with aplomb while directing the Division of Neonatal-Perinatal Medicine at Johns Hopkins University. Ned increased the Editorial Board to 36 members to serve the growing and diversifying field of perinatology. His services to both the Journal and the field of neonatal-perinatal medicine are unmatched. His influence touched patients across the globe. Personally, he was a tremendous help in the transition, providing spreadsheets, documents, and other materials, as well as specially prepared "Ned's Notes" to help keep the Journal running smoothly. On behalf of the entire field of neonatal-perinatal medicine, I thank Ned for his service and wish him well with clear sailing on calm seas as he pursues his passion, sailing his beloved boat.

As a way of introduction, I was initially a journalism major at Ohio State University before changing to biology. After attending Northeast Ohio Medical Universities, I was a resident and chief resident at Cincinnati Children's Hospital Medical Center. After obtaining fellowships in neonatal-perinatal medicine and molecular genetics at Yale University, I joined the faculty, where I have been ever since. I run a funded research laboratory focusing on the genetics and genomics of normal and perturbed erythropoiesis, especially inherited disorders of the

\footnotetext{
Patrick G. Gallagher, Editor-In-Chief, Journal of Perinatology patrick.gallagher@yale.edu

1 Department of Pediatrics, Pathology, and Genetics, Yale University School of Medicine, New Haven, CT, USA

2 Yale New Haven Childrens Hospital, New Haven, CT, USA
}

erythrocyte. I am interested in infectious diseases, genetic disorders, and, to be honest, just about everything. I have also participated in editorial duties for a number of scientific and medical journals.

Naming a new Editor-in-Chief brings opportunities to strengthen and expand the Journal, enacting novel initiatives, and engaging members of the neonatal-perinatal medicine community. The Journal will continue to have a wide scope, covering many relevant areas, including practice, quality improvement, education, technology, politics, ethics, transport, professional issues, and administration.

Regular Articles, highlighting the best research in the field, are the bedrock of the Journal. Review Articles, which have been very popular, will be expanded. Examples of upcoming reviews include use of oral glucose gel in the management of hypoglycemia and neurorehabilitation for neonatal brain injury. While Review Articles are by invitation, readers with ideas for important topics are encouraged to contact the Editorial Offices with their suggestions.

Comments are being formalized as an official article type in the Journal. These will typically be by invitation and will be published in conjunction with related, relevant Review or Regular articles. Thus, after soliciting Review Articles by leaders in the field, clusters of articles on specific topics will be published together, addressing current clinical, mechanistic, therapeutic, and future directions of a wideinterest area or problem. Upcoming thematic article clusters include controversies in diagnosis and management of patent ductus arteriosus, and updates in the use of genetic and genomic techniques in diagnosis and management of inherited disorders in the fetus and newborn.

The Journal will also continue to publish Quality Improvement (QI)-related articles. The ongoing QI review series has been popular and the number of QI studies submitted to the Journal continues to rise. The drive for excellence in this emerging field continually raises the bar for publication of QI studies.

The Editorial staff of the Journal of Perinatology is also evolving. A Deputy Editor has been added to contribute ideas, enact new initiatives, handle Journal of Perinatology 
Supplements, and to share editorial and review responsibilities to keep manuscript processing time at a minimum. I was delighted when Dr. Tonse Raju agreed to take on the Deputy Editor position. Dr. Raju brings the experience of two careers, one as a neonatologist in Illinois, the other as a Program Officer and Branch Chief at the Eunice Kennedy Shriver National Institute of Child Health and Human Development (NICHD). Since joining the Editorial team in February, Dr. Raju has been an absolute delight to work with.

Our publisher, Springer Nature, is leading the charge on best practices and standards in biomedical publishing. Their initiatives have led to a number of improvements for the Journal. One initiative is establishing Editor, Associate Editor, and Editorial Board member terms. Rotation of Editorial Board members allows a journal to maintain an institutional memory while continually adding the energy, enthusiasm, and ideas of new members. We are thankful to our current Associate Editors, Drs. Yvonne Cheng, Jane McGowan, Francis Mimouni, Stephen Pearlman, and Jonathan Swanson. We thank Drs. Arun Primanik and Jatinder Bhatia, who finished terms in December 2018, and agreed to remain on the Editorial Board. We are also thankful to our Editorial Board. Keeping with the Springer Nature model, a similar rotation of the Editorial Board will occur, with some finishing terms at the end of the year to be replaced by new members. As this process goes forward, we are striving for an Editorial Board marked by diversity-in gender, ethnicity, race, interests, career stage, and geographic location.

Another transition for the Journal this year has been the departure of Publishing Manager Nickie Roake. Nickie was a big help at the beginning of the year as we transitioned editorial duties. We wish her well in her new endeavors. We were excited when we learned Dr. Rebecca Shreeve would be joining our editorial team, bringing her experience in translational cancer research and biomedical publishing to the Journal. Anastasiya Netrunenko, Publishing Assistant, and Hodan Omar, Editorial Assistant, have joined Becky in the Editorial offices in London. Chantal Botha, Senior Production Editor, another important member of the team, keeps things running smoothly on the production side. We look to Becky, Anastasiya, Hodan, and Chantal to help us improve both the submission and review processes, develop new content, layout, structure, increase visibility, and continually update the Journal of Perinatology's appearance. As a testament to our team's progress, in just a few short months, the time from submission to first decision of manuscripts undergoing full review has decreased from 65 days to 50 days, and the time to first decision of manuscripts without review has decreased from 23 days to 7 days.

The Journal of Perinatology has been the official publication of the American Academy of Pediatrics (AAP) Section on Neonatal Perinatal Medicine (SoNPM) and the National Perinatal Association (NPA). Moving forward, we aim to enhance and expand the long-standing relationship of the Journal with these societies. I thank John Zupancic, Mark Hudack, and Lily Lou from the SoNPM and Mitchell Goldstein from the NPA for their help and guidance. The Journal is committed to continuation of the popular "AAP Journal Club" sponsored by the SoNPM and the International Society for Evidence-Based Neonatology (EBNEO). The AAP Journal Club is focused toward trainees and the review process is designed to be an educational experience. Additional details can be found at https://www.aap.org/enus/about-the-aap/Committees-Councils-Sections/NeonatalPerinatal-Medicine/Neonatologist/Pages/Journal-Club.aspx.

Another exciting initiative we are pursuing with the SoNPM is our Editorial Board Mentoring InitiaTive (EDIT). Together, a senior and an early career faculty member or trainee are appointed to the Editorial Board. Manuscripts are assigned to both, who together produce a single review for the Journal. The goal is to combine mentoring with real-world experience. Early feedback has been enthusiastic.

The Journal of Perinatology belongs to the neonatal - perinatal community. With your input, the Journal will continue to evolve to serve the community in whatever capacity needed. We solicit your advice and suggestions on journal-related matters via email at jperinatol@us.nature. com.

\section{Compliance with ethical standards}

Conflict of interest The author declares no conflict of interest.

Publisher's note: Springer Nature remains neutral with regard to jurisdictional claims in published maps and institutional affiliations. 